\title{
Abdominal Physical Signs and Medical Eponyms: Movements and Compression
}

\author{
Vaibhav Rastogi, MD; Devina Singh, MD; Halil Tekiner, PhD; Fan Ye, MD; \\ Joseph J. Mazza, MD; and Steven H. Yale, MD
}

\begin{abstract}
Background: Prior to the advent of modern imaging techniques, maneuvers were performed as part of the physical examination to further assess pathological findings or an acute abdomen and to further improve clinicians' diagnostic acumen to identify the site and cause of disease. Maneuvers such as changing the position of the patient, extremity, or displacing through pressure a particular organ or structure from its original position are typically used to exacerbate or elicit pain. Some of these techniques, also referred to as special tests, are ascribed as medical eponym signs.

Data sources: PubMed, Medline, online Internet word searches, textbooks and references from other source text. PubMed was searched using the Medical Subject Heading (MeSH) of the name of the eponyms and text words associated with the sign.

Conclusion: These active and passive maneuvers of the abdomen, reported as medical signs, have variable performance in medical practice. The lack of diagnostic accuracy may be attributed to confounders such as the position of the organ, modification of the original technique, or lack of performance of the maneuver as originally intended.
\end{abstract}

Keywords: Eponyms; Medical signs; Medical maneuvers; Special tests

$\mathrm{M}$ ovement of the patient or extremity or compression of an organ is performed during the physical examination of the abdomen to narrow the differential diagnosis or confirm a particular disease process. Compression refers to the movement against a fixed structure thus causing a reduction in volume. Ballottement, another maneuver performed during the physical examination, involves the kidney, fluid within the knee, organ or mass in ascitic fluid, and the pregnant uterus. It is derived from the French word "tossing", from ballotter, to toss about, or up (ballote, a ball). ${ }^{1}$ Francois Louis Joseph Solayrès de Renhac initially used the term during the 18th century in reference to the return impact of the fetus felt after a push with a finger against the uterine wall or a "rise and falls back." Observing the effects caused by these movements assists physicians in identifying the location of pain and determining the possible cause of the disease. Many such diagnostic maneuvers have been assigned eponyms over the year, and these are discussed,

Corresponding Author: Steven H. Yale, MD, University of Central Florida College of Medicine, Department of Internal Medicine, 6850 Lake Nona Blvd, Orlando, FL 32827, Email: steven.yale.md@gmail.com along with brief historical information and application in modern day clinical practice (Table 1). The signs are presented sequentially based on the year they were first reported.

\section{Data Sources}

PubMed, Medline, online Internet word searches, and bibliographies from source text and textbooks were used. PubMed was searched using the Medical Subject Heading (MeSH) of the name of the eponyms and text words associated with the sign.

\section{Howship-Romberg Sign}

John Howship (1781-1841) was born in London, England and attended medical school in 1799. He was appointed assistant surgeon at St. George's infirmary, London in 1805, and in 1834 was assistant surgeon to the Charing Cross Hospital, and subsequently, chief surgeon in 1836 . He was a member of the Royal College of Surgeons from 1828 to 1841 and

Received: March 16, 2018

Revised: July 25, 2018

Accepted: September 26, 2018

doi: $10.3121 / \mathrm{cmr} \cdot 2018.1422$ 
delivered the prestigious Hunterian Oration, a lecture at the Royal College of Surgeons in 1833. He was a member of the Royal Medico-Chirurgical Society of London, MedicoChirurgical Society, and Royal Medical Society Edinburgh, Copenhagen Royal Academy of Medicine, Society for Natural and Medical Sciences, Dresden; Academy of Naturae Curiosi, Bonn, and corresponding member of the Société Médicale d'Emulation, Paris. ${ }^{2}$ His contribution spanned the fields of gastroenterology, genitourinary, and disorders of bone. ${ }^{3}$ Another sign that bears his name is the "lacuna sign," which references the groove or bone pit containing osteoclast cells indicative of bone resorption.

In his book entitled Practical Remarks on the Discrimination and Appearance of Surgical Disease, Howship (1840) (Table 1) reported a case entitled "Strangulated Thyroidal HerniaDiagnostic Symptom-Appearances on Dissection" in an aged female under the care of Mr. Weatherfield:

In November she was seized with violent spasmodic pain in the left side of the abdomen running down the left leg, with sickness, vomiting, and, as she said, diarrhoea. ${ }^{4(\mathrm{p} 323)}$ (...) March 23, 1839- Mr. W. found her again suffering under extreme pain and tenderness in the abdomen, especially in the left side, with constant vomiting, preceded by diarrhoea, and attended with the same pain as before, down the left leg. The symptoms, those of strangulated hernia, Mr. W. made a careful inquiry and examination but could nowhere ascertain outward tumour. ${ }^{4 \text { (p. 324) (emphasis added) }}$

On postmortem evaluation he found,

On opening the abdomen, a portion of small intestine was seen stretched towards the obturator foramen, where a knuckle was firmly impacted, forming a small hernia, no larger than a nutmeg, protruding through the opening. The intestine, highly inflamed, was almost gangrenous. The parts were carefully removed and admirably dissected; demonstrating the hernia to the best advantage. ${ }^{4 \text { (p. 324) }}$

Moritz Heinrich Romberg (1795-1873) was born in Meiningen, Saxony in 1795, and received his medical degree from the University of Berlin in $1817 . .^{5} \mathrm{He}$ was appointed medical officer for the poor in 1820 . In 1830, he received the title Privatdozent (PD) an academic title assigned to one who is qualified to teach a subject at the university without being

Table 1. Summary of Abdominal Physical Signs involving Movement and Compression (1840-1955)

\begin{tabular}{lllll}
\hline Sign & Year & \multicolumn{1}{c}{ Description } & Sensitivity & Specificity \\
\hline Howship- & $1840-$ & $\begin{array}{l}\text { Pain and paresthesia located at the medial side of the thigh and } \\
\text { the inability to adduct the thigh. Entrapment of the small bowel in } \\
\text { the obturator canal may lead to ileus, incarceration, and } \\
\text { strangulation of the hernia sac. }\end{array}$ & Unknown & Unknown \\
\hline Boyce & 1848 & $\begin{array}{l}\text { In cases of esophageal diverticulum (pouch) bilateral pressure } \\
\text { over the esophagus just below the cricoid cartilage causes gas in } \\
\text { the mouth. Asking the patient to swallow } 2 \text { to } 3 \text { times can produce } \\
\text { this same finding. }\end{array}$ & Unknown & Unknown \\
\hline
\end{tabular}

For detecting chronic appendicitis, the patient is in a sitting position with the examiner to the right of the patient. The examiner palpates the lateral edge of the rectus abdominal muscle at a site located midway between the anterior superior

Bassler 1913 iliac spine and umbilicus. With the thumb pushed posteriorly (1/2 the distance of the abdominal cavity), it is than swung to the right

Unknown Unknown at a right angle to the downward pressure line. This maneuver pinches the appendix against the iliac muscle and structures producing pain or tenderness.

\begin{tabular}{|c|c|c|c|c|}
\hline Cope & 1919 & $\begin{array}{l}\text { Thigh-rotation test or obturator test. The examiner stands to the } \\
\text { right of the patient with the right thigh slightly flexed. The limb is } \\
\text { then fully rotated at the hip, first internally and then externally. }\end{array}$ & $8 \%$ & $94 \%$ \\
\hline Cope & 1921 & $\begin{array}{l}\text { Iliopsoas rigidity or psoas extension test. The patient is lying in } \\
\text { the lateral decubitus position opposite the side where the pain is } \\
\text { located. Extension of the thigh causes pain. }\end{array}$ & $13 \%-42 \%$ & $79 \%-97 \%$ \\
\hline Alders & 1951 & $\begin{array}{l}\text { In a gravid female with a palpable uterus with the patient in a } \\
\text { supine position, the examiner locates the site of maximum pain } \\
\text { on the abdominal wall. With fingers remaining at this site, turn the } \\
\text { patient to the opposite side to a lateral decubitus position. If the } \\
\text { pain lessens or disappears, then it is of uterine origin. Referred to } \\
\text { as "shifting tenderness". }\end{array}$ & Unknown & Unknown \\
\hline Bryan & 1955 & $\begin{array}{l}\text { In appendicitis, pressure on a pregnant uterus from the left side } \\
\text { will often elicit pain in the right lower or middle quadrant. }\end{array}$ & Unknown & Unknown \\
\hline
\end{tabular}


a professor. In 1830 and again in 1836, he served as director of the cholera hospitals in Berlin. In 1838, he was appointed extraordinary professor of medicine and Director of the University Polyclinc and received the title ordinary professorship at the University of Berlin in $1845 .^{6,7}$ His most widely recognized work published from 1840 to 1846 and translated in English in 1853 was a treatise on the Nervous Diseases of Man, where he described another better known neurological sign related to involvement of the dorsal column of the spinal cord in patients with tabes dorsalis. Dr. Romberg is the author of other works on cholera and respiratory paralysis, among others. ${ }^{6,8} \mathrm{He}$ described the significance of his findings of an obturator hernia in 1848 (Table 1):

What gives this case a special interest is not that it is rare, but elucidating the diagnosis by its neurologic phenomenon. Pressure and distortion of the obturator nerve must be found in every hernia obturatoria, and if the content of the hernia is a bowel disease, symptoms of nerve entrapment will be associated with the symptoms of intestinal entrapment. Both the sensory fibers of the obturator nerve, which spread as cutaneous nerves on the inner side of the thigh, as well as the motor-fibers, destined for the muscles gracilis and adductors of the thigh, will manifest this disorder by more or less severe pain located in the inner side of the thigh, stiff with paresthesia, and the inability to adduct the thigh. In some older observations, we find a mention of this pain accompanying an existing ileus, without it having any value in diagnosis. ${ }^{9}$ (p. 624) (emphasis added)

He explained the diagnostic criteria for obturator hernia (Table 1):

For the hernia obturatoria is a diagnostic criterion as it is associated with pain, disturbed movement of the thigh, and altered intestinal movement. Most important, because this condition is chronic it rarely forms a tumor visible from the outside, and is subjected to temporary, repeated incarceration. Circumstances occurring in the female sexes, where this hernia is more likely to occur, may lead to the assumption of a nervous, hysterical affection, in which the misinterpretation of the pain on the thigh as a neuralgic is all the more likely to confirm the diagnosis. ${ }^{9}(\mathrm{p}$. 625) (emphasis added)

Hence, Howship was the first to describe the clinical syndrome, while Romberg reported on the diagnostic criteria and explained the pathophysiology of an incarcerated obturator hernia. The Howship-Romberg sign was identified in 11 of 30 patients $(37 \%)$ with obturator hernia. ${ }^{10}$ In another small study, the Howship-Romberg sign was present in only 3 of 13 patients. ${ }^{11}$ It has been shown to be present in $\mathbf{1 5 \%}$ to $50 \%$ of cases of obturator hernia. ${ }^{12}$

The obturator hernia may follow the route of the branch of the anterior or posterior obturator nerve or between the internal and external obturator membranes. The different route that the obturator hernia takes as it enters the obturator canal explains the lower detection rate of this sign in some patients. Thus, the sign was shown to occur more commonly in patients when the hernia follows the anterior branch of the obturator nerve, which innervates the muscles of the pectineus, adductor brevis, and longus and gracilis. ${ }^{13}$

In a study of 43 patients, comparison of those with obturator hernia before and after the advent of computed tomography (CT) of the pelvis showed that there was a better preoperative diagnostic accuracy and a lower rate of intestinal resection and surgical mortality with pre-operative CT. ${ }^{14}$ In another small study, no difference was found in the time to operation, length of stay, need for bowel resection, and mortality rate, regardless of whether a patient received preoperative CT. ${ }^{10}$

\section{Boyce Sign}

The sign was named after Dr. Albert Boyce Barrow (18471939), although Drs. Barrow and Joseph Cunning (18721948) jointly reported the sign. ${ }^{15}$ Dr. Barrow was born in Newmarket, England and received his medical degree in 1873 from King's College in London. ${ }^{16} \mathrm{He}$ was appointed to the following positions during his initial career at King's College Hospital: 1874-1875, house surgeon; 1875, Sambrooke surgical registrar; and 1876, pathological register. ${ }^{17}$ In 1880, he was a surgeon in the Westminster Dispensary and assistant surgeon at the West London Hospital in $1882 .{ }^{18}$ From 1882 to 1886 , he served as assistant surgeon at the Westminster Hospital, and at the Royal Free Hospital, Barrow was appointed assistant surgeon in 1883, full surgeon in 1888, and consulting surgeon in $1905 .{ }^{19}$ In 1886 , he returned to King's College Hospital as assistant surgeon. He was elected member in $1873,{ }^{20}$ and Fellow of the Royal College of Surgeons (FRCS) England in $1875 .^{21}$ In 1893, he achieved the rank of full surgeon at King's College Hospital, ${ }^{22}$ and was consulting surgeon and Fellow until his retirement in 1912. ${ }^{24}$ His other accolades include being a member of the British Medical Association from 1880 to 1917 and Member of Council for the Royal Medical and Chirurgical Society in $1903 .^{23}$

Joseph Cunning was born in Victoria, Australia and received his medical degree from Melbourne University. From 1895 to 1899, he served as house surgeon and physician at Melbourne Hospital followed by a Fellowship position at St. Bartholomew's Hospital in 1901. At the Royal Free Hospital, he moved up the rank from senior resident medical officer in 1901, to assistant surgeon in 1905, and senior surgeon from 1919 to $1931 .^{24} \mathrm{He}$ also served as surgeon to the Royal Cancer Hospital and Victoria Hospital for Children in 1905. ${ }^{25}$ Dr. Cunning was president of the Association of Australian and New Zealand Medical Men in England, and in 1932 was elected Fellow of the Royal Australasian College of Surgeons. ${ }^{24} \mathrm{He}$ was Assistant Surgeon at the Royal Free Hospital at the time of his and Barrow's publication entitled, "A Case of Oesophageal Pouch Successfully Treated by Excision." He, along with Cecil A. Joll, published a book entitled Aids to Surgery (Students' Aids Series) in 1904. ${ }^{26}$ 
In 1905, Barrow and Cunning reported the case of a woman, aged 55 years, in their paper, "A Case of Oesophageal Pouch Successfully Treated by Excision" (Table 1):

During the previous six months there was a marked increase in the difficulty of swallowing solid food. She volunteered the information that she had regurgitated, not vomited, food quite unchanged as long as three days after taking it. As instances, she gave a pickled onion and portions of rabbit. She also complained that stooping caused regurgitation and that she made a curious noise on swallowing. The patient looked so thin and half-starved that several surgeons who saw her were tempted to say, "Oh! She looks as if she had malignant disease." On examination of the neck no swelling or enlargement of the glands could be detected, but on bilateral pressure over the oesophagus just below the level of the cricoid cartilage, a certain amount of gas could be squeezed up into the mouth. On swallowing two or three times gas could again be squeezed up. A medium sized bougie stopped eight inches from the teeth and could be felt to the left of the trachea. A small bougie could be passed into the stomach. (...) An oesophageal pouch was now suspected from the history of regurgitation of unchanged food and from being able to squeeze up gas on pressure at the base of the neck. Two bougies were passed together. The first went into the pouch, the second into the stomach. ${ }^{15}$ (pp. 928-929) (emphasis added)

In 1914, Jackson wrote the first description of Boyce sign in his chapter "Disease of the Esophagus":

Boyce's sign can usually be elicited immediately after swallowing. It consists in a gurgling sound produced by pressure of the hand on the side of the neck. A fresh swallowing movement without food or water is needed for each test. The sound is probably made by forcing out of air and bubbles of secretion from the sac. All symptoms are valueless diagnostically but they are urgent indications for esophascopy. ${ }^{27}$ (pp. $\left.545-55\right)$

In 1922, Jackson wrote this description of Boyce sign in his book chapter on "Diverticulum of the Esophageal":

The Boyce sign is almost invariably present, and is diagnostic. It is elicited by telling the patient to swallow, which action imprisons air in the sac. The imprisoned air is forced out by finger-pressure on the neck, over the sac. The exit of air bubble produces a gurgling sound audible at the open mouth of the patient. ${ }^{28 \text { (pp. 263-264) }}$

It should be recognized that Dr. Barrow's middle name was used to describe this sign, contrary to the usual convention. It is also unusual that the name Cunning was not hyphenated with Barrow's, since they were both named authors on the publication. There are no studies evaluating the sensitivity or specificity of the sign.

\section{Bassler Sign}

Anthony Bassler (1874-1959) graduated from Bellevue Hospital Medical College in 1889. In 1911, he and Dr. Lewis
Brinton were appointed editors of The American Journal of Gastroenterology. ${ }^{29}$ In 1916, Bassler was appointed consulting gastroenterologist to Christ's Hospital, Jersey City, NJ, and again along with Dr. Lewis Brinton from Philadelphia, editors of Proctologist and Gastroenterologist. ${ }^{30}$ In 1918, Bassler was appointed professor of gastroenterology at Fordham University Medical School, New York. In 1920, he published his book Diseases of the Intestines and Lower Alimentary Tract while serving as Professor of Gastroenterology at the Fordham University Medical School and New York Polyclinic Medical School and Hospital. He was president and later honorary president of the National Gastroenterological Association, president of the New York Gastroenterological Association, and first chairman of the Section of Gastroenterology of the American Medical Association. ${ }^{31} \mathrm{He}$ was also active in international societies, including serving as the American President of the International Society of Gastroenterology and Hepatic Insufficiency. ${ }^{31} \mathrm{He}$ received numerous other accolades including being decorated a Légion d'honneur of France and honorary LL.D. from Hahnemann Medical College in Philadelphia. ${ }^{31}$ The memorandum published in the American Journal of Gastroenterology by his colleagues speaks of his accomplishments, devotion, contributions, and service to the field and practice of gastroenterology, as well as his humanistic and selfless qualities. ${ }^{31}$ Among his many accomplishments, he developed a "string test" used to determine the presence and location of an ulcer. ${ }^{32}$ Bassler (1913) described a method for compressing the appendix to assist in diagnosing chronic appendicitis (Table 1):

[n] ote the position of the right edge of the rectus muscle on the umbilical-spine line maintaining the site with a finger. Having the patient rise to a sitting position helps in palpating for the rectus edge. Standing at the right and facing the patient (for right-handed individuals) the thumb is vertical on the abdomen, the tip of the thumb pointing to the ensiform, when it is slowly pressed backward into the abdomen, not inward, outward, up or down. When the thumb has been sunk about half-way down to the back of the abdominal cavity, it is swung to the right of the patient at a right angle to the downward pressure line. This pinches the appendix against the iliacus muscle and unyielding structures under and at the side of it, and usually elicits pain or tenderness. It is well, having done this in the middistance between the anterior superior spine and the umbilicus and not having obtained tenderness, to move the thumb down about one-half inch, performing it again, and so on downward until one has reached almost to the brim of the pelvis. ${ }^{33}$ (pp. 207-208) (emphasis added)

Bassler stated that this method was particularly useful in obese patients and in cases were percussion cannot identify the cecum. ${ }^{33}$ Through downward and right lateral pressure, it was useful to detect chronic appendicitis. ${ }^{33} \mathrm{We}$ are unaware of any studies that have evaluated the sensitivity or specificity of this sign. 


\section{Cope Psoas and Obturator Signs}

Sir Vincent Zachary Cope, MD, MS, FRCS (1881-1974) was an English surgeon born at Hull and graduated from St. Mary's Hospital medical school with honors. He served there as a surgeon and consultant throughout his career. ${ }^{34} \mathrm{He}$ joined the Royal Army Medical Corps in 1914 and served in World War I from 1916 to $1919 .{ }^{34}$ Cope published his first book on the surgical aspect of dysentery including liver abscess in 1920 , based on his experience caring for soldiers inflicted with this condition. ${ }^{34} \mathrm{He}$ served the Royal College of Surgeons as a member of the Court of Examiners and Council ${ }^{34}$ and was chairman of committees to the Ministry of Health responsible for surveys of hospital facilities, workforce and training, editing these important reports from 1949 to $1952 .{ }^{35} \mathrm{He}$ authored the textbook The Early Diagnosis of the Acute Abdomen from 1921 until 1972.35 Cope contributed substantially to the medical, historical, biographical literature and had an exemplary record of public service, for which he was honored by being knighted in $1953 .{ }^{35}$

In 1921, Cope described the maneuver for determining iliopsoas rigidity in The Early Diagnosis of the Acute Abdomen, as revised by Silen (Table 1):

It is well known that if there be an inflamed focus in relation to the psoas muscle the corresponding thigh is often flexed by the patient to relieve the pain. A lesser degree of such contraction (and irritation) can be determined often by making the patient lie on the opposite side and extending the thigh on the affected side to the full extent. Pain will be caused by the maneuver if the psoas is rigid from either reflex or direct irritation. ${ }^{36 \text { (p. } 36) \text { (emphasis added) }}$

The iliopsoas rigidity test, or psoas extension test, is used clinically to identify a retrocecal appendicitis,${ }^{37}$ primary psoas abscess, or psoas abscess secondary to paraspinal or urologic conditions ${ }^{38}$ The test may be positive due to the apposition of an inflamed retrocecal appendix against the psoas muscle, and in severe cases, the inflammation may cause a fixed flexion deformity of the right hip. ${ }^{37}$ Cope also accounted for when the psoas test is most likely to be positive: "The value of the test is diminished if the anterior abdominal wall is rigid. The psoas test is not so often positive when the inflammation becomes subacute." 36 (p. 36) The psoas sign has a sensitivity ranging from $13 \%$ to $42 \%$, specificity of $79 \%$ to $97 \%$ and a positive likelihood ratio of 2.0 for detecting appendicitis. ${ }^{39,40}$ The positive and negative likelihood ratios for psoas sign, as described in a meta-analysis by Andersson et $\mathrm{al}^{41}$ are 2.31 (1.36-3.91) and 0.85 (0.76-0.95), respectively. Thus, a patient with a positive test result is likely to have appendicitis. Conversely, a negative test result has only a small effect on decreasing disease probability. The name Vasily Parmenovich Obraztsov has been associated with this psoas sign. ${ }^{42}$ In a study of 19,346 patients, Obraztsova sign was found in $62.1 \%$ of patients with acute appendicitis and $3.7 \%$ of patients with retro-appendicitis. ${ }^{43}$ The names Obraztsov-Strazhesko have also been attributed to a sliding palpation technique for deep abdominal palpation. ${ }^{44}$
The thigh-rotation test is performed as Cope described in 1919 (Table 1):

The right thigh is slightly flexed (so as to relax the psoas muscle) by the surgeon, who stands on the right of the patient: the limb is then fully rotated at the hip, first internally and then externally, so as to put the obturator internus through a full range of movement. The sign is positive if the patient complains of hypogastric pain when the limb is moved in this manner. ${ }^{45}$ (emphasis added)

Cope further explained when the obturator test is most likely to be positive:

Since the fascia covering the obturator internus is fairly dense, the test is not positive unless the inflammation is considerable; and, with a positive result, one always expects the appendix to be adherent to, or even an abscess to be contiguous to, the fascia. I have found this sign of assistance not only in cases of appendicitis, but also in other pelvic conditions such as rupture ectopic gestation, and I have no doubt that it will often prove of value in doubtful cases. ${ }^{45}$

The obturator test is positive due to conditions that irritate the obturator internus muscle such as inflammatory fluid in the pelvis, abscess, or perforated appendix. An inflamed appendix located in the pelvic brim may cause a positive test when apposed against the obturator internus muscle. ${ }^{37}$ The obturator sign has a low sensitivity $(8 \%)$ and high specificity $(94 \%)$ in diagnosing acute appendicitis. ${ }^{40}$

\section{Alders Sign}

Nicholas Alders (1904-1995) was born in Budapest and received his medical degree in Vienna in 1928. He practiced as an obstetrician and gynecologist and was forced to flee from Vienna to England in 1938 during World War II. In England, he served initially in the Emergency Medical Services followed by an appointment as a resident medical officer in 1948. This was followed by an appointment as a Parstime Consultant in the Department of Obstetrics and Gynecology at the Royal Victoria Hospital, Bournemouth in 1954. He also served in East Dorset Group of Hospital, SouthWest Metropolitan Regional Hospital Board, that same year. ${ }^{46}$ He was appointed Fellow of the Royal College of Surgeons of England (FRCSE) in 1945 and Member, Royal College of Obstetricians and Gynecologists (MROG) ${ }^{46}$

In 1951, he described a maneuver in his paper entitled "A sign for differentiating uterine from extrauterine complications of pregnancy and puerperium" published in the British Medical Journal. This sign was used to distinguish extrauterine from uterine causes of right lower quadrant abdominal pain during pregnancy (Table 1):

With the patient lying straight on her back, the examining fingers find the area of maximum tenderness to pressure on the abdominal wall. While the fingers remain in contact with that area without altering the intensity of pressure they are exerting to elicit pain, the patient is made to turn over on the opposite side so that the plane of the anterior 
abdominal wall is approximately vertical. The pain produced by the pressure of the fingers will be less or will have entirely disappeared if the lesion is uterine and has fallen away from the examining fingers- "shifting tenderness" 47 (pp. 1194-1195) (emphasis added)

Thus, if the pain is uterine (eg, hemorrhage, leiomyoma) in origin the pain will be less or disappear when the patient turns to the opposite. However, if the pain is extrauterine in origin (eg, appendiceal, ovarian torsion, diverticulitis, disease of the kidney or gallbladder) it will remain unaltered or be of fixed tenderness. He further discussed the limitations of this sign:

It is obvious that this sign can be of use only if the uterus is large enough to be palpable abdominally, and that it may be misleading in the rare case in which a uterine lesion has become fixed by adhesions to the anterior abdominal wall. In acute salpingitis, which does occur in pregnancy (Lennon, 1950), the result of the test will depend on the presence or absence of perisalpingitic adhesions. ${ }^{47(p .1195)}$

It has been reported that approximately $36 \%$ of pregnant patients with appendicitis had a positive Alders's sign.$^{48}$ In rare patients, when the uterus is adherent to the anterior abdominal wall, the sign underestimates uterine size. ${ }^{47}$ Tamir et al and Brown found this sign not to be useful in clinical practice. ${ }^{49,50}$

\section{Bryan Sign}

Williams McIver Bryan, Jr. (1917-2007) was born in Savannah, Georgia and graduated from the Medical College of South Carolina in 1944. He received a Master of Science degree and was the Fred Adair Teaching Fellow in Obstetrics and Gynecology at the University of Tennessee College of Medicine, Memphis..$^{51}$ In 1950, he served in the Department of Obstetrics and Gynecology at Columbia General Hospital, South Carolina. ${ }^{51} \mathrm{He}$ was the Chief of Obstetrics and Gynecology at Columbia Hospital (currently Palmetto Richland Memorial Hospital) and was a consultant at Baptist Medical Center, Richland Memorial, and Providence Hospitals in Columbia. ${ }^{51}$

Dr. Bryan was a diplomat of the American College of Obstetricians and Gynecologist, Fellow of the American College of Physicians, and Life Fellow of the American College of Obstetricians and Gynecologists. ${ }^{51} \mathrm{He}$ served as president of the South Central Obstetrical and Gynecological Society. During World War II and the Korean War, he served as Naval Medical Officer. ${ }^{51} \mathrm{He}$ was a member of the Board of Directors of the American Red Cross United Fund and Committee on Maternal Welfare for the State of South Carolina. ${ }^{51}$

In his presentation at the Seventeenth Annual Meeting of the South Atlantic Association of Obstetricians and Gynecologist (1955), Bryan described a paper entitled "Surgical Emergencies in Pregnancy and in the Puerperium" (Table 1): "Pressure on the pregnant uterus from the left side will often elicit pain in the right lower or middle quadrant." 52 (p. 1205) (emphasis added) Kurtz et $a{ }^{53}$ found that Bryan sign had an accuracy rate of $83.8 \%$ followed by rebound tenderness $(68.6 \%)$ in diagnosing appendicitis during pregnancy. Both signs were associated with a high false positive rate. ${ }^{54}$ Two signs, Alder and Bryan signs, are the only known signs consistently found during pregnancy. ${ }^{55}$

\section{Conclusion}

Movement and compression techniques are used during the physical examination to elicit symptoms or confirm clinical suspicions about a disease process. Unfortunately, these clinical skills are often neglected and relegated in favor of more sophisticated imaging techniques. Some of these signs have known pathophysiologic mechanisms that provide pragmatic explanations of why symptoms occurred with the maneuvers. A detailed history used in conjunction with some of these techniques may still be helpful to clinicians in narrowing their differential diagnosis or confirming a disease process.

\section{References}

1. Skinner A. The origin of medical terms. Baltimore: Williams \& Wilkins Co; 1949.

2. Howship J. Observation in surgery and morbid anatomy with cased dissection and engraving. In: Longman, Hurst, Rees, Orme, and Brown. The anatomy and physiology of the human body. London: Paternoster-Row; 1817.

3. Bir SC, Kalakoti P, Notarianni C, Nanda A. John Howship (1781$1841)$ and growing skull fracture: historical perspective. J Neurosurg Pediatr. 2015;16(4):472-476.

4. Howship J. Practical remarks on the discrimination and appearance of surgical disease; with an appendix containing the descriptive catalogue of the author's collection in pathological anatomy and the Hunterian Oration for 1833. Strangulated Thyroideal Hernia-Diagnostic SymptomAppearances on Dissection. London: John Churchill; 1840. 323-324.

5. Firkin BG, Whitworth JA. Dictionary of medial eponyms. Boca Raton, FL: The Parthenon Publishing Group A CRC Press Company; 2002.

6. Romberg M. Obituary Record, Medical News. The Medical News 1873;31-32:135.

7. Obituary. Moritz Heinrich Romberg. The Medical Times and Gazette: A Journal of Medical Science, Literature, Criticism, and News. 1873;2:81.

8. News and Miscellany. Death of Romberg. The Medical and Surgical Reporter. A Weekly Journal 1873;29:88

9. Romberg. Die Operation des eingeklemmten Bruches des eirunden Loches. Operatio hernia foraminis ovales incarceratae. In: Dieffenbach JF ed. Die operative chirurgie, Zweiter Band. Leipzig: F.A. Brockhaus 1847;619-625.

10. Nasir BS, Zendejas V, Ali SM, Groenwald CB, Heller SF, Farley DR. Obturator hernia: the Mayo Clinic experience. Hernia. 2012;16(3):315-319.

11. Yip AW, AhChong AK, Lam KH. Obturator hernia: a continuing diagnostic challenge. Surgery. 1993;113(3):266-269.

12. Mantoo SK, Mak K, Tan TJ. Obturator hernia: diagnosis and treatment in the modern era. Singapore Med J. 2009;50(9):866-870.

13. Karasaki T, Nakagawa T, Tanaka N. Obturator hernia: the relationship between anatomical classification and the Howship-Romberg sign. Hernia. 2014:18(3):413-416. 
14. Kammori M, Mafune K, Hirashima T, et al. Forty-three cases of obturator hernia. Am J Surg. 2004;187(4):549-552.

15. Barrow AB, Cunning J. A Case of Oesphageal Pouch Successfully Treated by Excision. Lancet. 1905;1:928-929.

16. Obituary. A. Boyce Barrow, F.R.C.S. Consulting Surgeon, King's College Hospital. Br Med J. 1939:1207.

17. Curnow J. King's College and King's College Hospital. A historical sketch. Kings College Hospital Reports; Being the annual report of King's College Hospital and the Medial Department of King's College. Volume VII (October 1, 1899-December 31, 1900). London: Aldard and Son; 1901. 2

18. Barrow, Albert Boyce (1847-1939). Plarr's Lives of the Fellows Online. Royal College of Surgeons. Created: 10 April 2013. Available at: https://livesonline.rcseng.ac.uk/biogs/E003812b. htm. Accessed December 7, 2017.

19. Thorne I. Sketch of the foundation and development of the London School of Medicine of the London School of Medicine for Women. London: G. Sharrow; 1905. 27.

20. The Medical Times and Gazette: A Journal of Medical Science, Literature, Criticism, and News. 1878;1:128.

21. Medical News. The Lancet. 1875;114(2938):931.

22. Fernandez L. The Medical Reporter: A Record of Medicine, Surgery, Public Health and of General Medical Intelligence. 1893;2(1):307.

23. Willett A. Royal Medical and Chirurgical Society. Br Med J. 1903:547.

24. Cunning, Joseph (1872-1948). Plarr's Lives of the Fellows Online. Royal College of Surgeons of England. Created: 20 June 2013. Available at: https://livesonline.rcseng.ac.uk/ biogs/E004130b.htm. Accessed December 8, 2017.

25. Appointments. Diary. Br Med J. 1905:287

26. Cushing H, Whitney JH. The Boston Medical and Surgery Journal. 1904;156:7.

27. Jackson C. Diseases of the esophagus-continued. In: Hageman JA, Killian G. Peroral endoscopy and laryngeal surgery. Saint Louis: The Laryngoscope Company; 1914. 540-556.

28. Jackson C. Bronchoscopy and esophagoscopy. A manual of peroral endoscopy and laryngeal surgery. Philadelphia and London: WB Saunders Company; 1922. 263-264.

29. The American Journal of Gastroenterology. News Items. NY Med J. 1911;94:1239.

30. New Note. Illinois Medical Journal. The Official Organ of the Illinois State Medical Society. April 1916;29:316.

31. Anthony Bassler, (1874-1959). Am J Gastroenterol. 1959;32:757-770.

32. Golden RL. A gift from Oxford: the Osler-Thomas connection. Proc (Bayl Univ Med Cent.) 2012;25(4):327-333.

33. Bassler A. Pinching the appendix in diagnosis of chronic appendicitis. Am J Med Sci. 1913;146(4):204-209.

34. Burke PF. The dexterous hand; Zachary Cope, surgeon and author 1881-1974. Surgical News. The Royal Australasian College of Surgeons. 2016;17(1):40-42.

35. Obituary: Vincent Zachary Cope, Kt., M.D., M.S., and F.R.C.S. Med Hist. 1975;19(3):307 308

36. Cope Z. Method of diagnosis: (II) The examination of the patient. Determination of illiopsoas rigidity In: Silen W, ed. Cope's early diagnosis of the acute abdomen. 17th ed. Oxford: Oxford Univeristy Press; 1921. 42.

37. Prabhu S. Clinical signs \& syndromes in surgery. New Dehli: Jaypee Brothers Medical Publishers; 2011.

38. Lee YT, Lee CM. Su SC, Liu CP, Wang TE. Psoas abscess: a 10 year review. J Microbiolo Immunol Infect. 1999;32(1):40-46.

39. Izbicki JR, Knoefel WT, Wiker DK, et al. Accurate diagnosis of acute appendicitis: A retrospective and prospective analysis of 686 patients. Eur J Surg. 1992;158(4):227-231.

40. Berry J, Malt RA. Appendicitis near its centenary. Ann Surg. 1984;200(5):567-575.
41. Andersson RE. Meta-analysis of the clinical and laboratory diagnosis of appendicitis. Br J Surg. 2004;91(1):28-37.

42. Augustin G. Acute Appendicitis. In: Heidelberg SC. Acute Abdomen During Pregnancy. Geneva, Switzerland: Springer International Publishing; 2014. 8.

43. Butsenko VN, Antoniuk SM. Significance of the separate symptoms in acute appendicitis. Klin Khir 1922;2(2):33-35. [Article in Russian].

44. Kovalyova ON, Aschcheulova TV. Percussion. In: Propedeutics to internal medicine Part 1: Diagnostics; Textbook for English learning students of higher medical schools. 2nd ed. Kiev: New Book Design; 2011. 58.

45. Cope VZ. The thigh-rotation or obturator test: A new sign in some inflammatory conditions. Br J Surg. 1919;7:537.

46. Appointments. Medical News. Br Med J. 1955;1(4906): 176.

47. Alders N. Sign for differentiating uterine from extrauterine complications of pregnancy and puerperium. Br Med J. 1951;2(4741):1194-1195.

48. Chen CF, Tan KH, Shin FC, Chen HI. Acute appendicitis during pregnancy. J Med Sci. 1999;19(9):256-262.

49. Tamir IL, Bongard FS, Klein SR. Acute appendicitis in the pregnant patient. Am J Surg. 1990;160(6):571-575; discussion 575-576.

50. Brown JJ, Wilson C, Coleman S, Joypaul BV. Appendicitis in pregnancy: an ongoing diagnostic dilemma. Colorectal Dis. 2009;11(2):116-122.

51. Obituary. Williams Bryan Jr. The Post and Courier. Powered by Legacy.com Available at: http://www.legacy.com/obituaries/ charleston/obituary.aspx?n=williamsbryan\&pid $=97086959 \&$ fhid $=5564$. Accessed December 27 , 2017.

52. Bryan WM Jr. Surgical emergencies in pregnancy and the puerperium. Am J Obstet Gynecol. 1955;70(6):1204-1211.

53. Kurtz GR, David RS, Sproul JD. Acute appendicitis in pregnancy and labor, a report of 41 cases. Obstet Gynecol. 1964;23(4):528-532.

54. Malathi KU. A case of acute appendicitis complicating pregnancy. The Antiseptic 1904;63:136-138.

55. DeSantis RA, Ernest G. Appendectomy during Pregnancy: A Survey of Two Army Medical Activities. Military Medicine 1999;164(10):671-674.

\section{Author Affiliations}

Vaibhav Rastogi, MD*; Devina Singh, MD广; Halil Tekiner, PhDf; Fan Ye, MD*; Joseph J. Mazza, MD§; and Steven H. Yale, $M D \uparrow$

*University of Central Florida, College of Medicine,

Orlando, Florida, USA

†University of Florida, Department of Medicine,

Gainesville, Florida, USA

tDepartment of the History of Pharmacy and Ethics, Erciyes

University School of Pharmacy, Talas, Kayseri, Turkey

\$arshfield Clinic Research Institute, Marshfield,

Wisconsin, USA

-Department of Internal Medicine, University of Central

Florida College of Medicine, Orlando, Florida, USA 